\section{Adult and Child Focus Group Views of Oranges and Mandarins}

\author{
Amalie B. Kurzer ${ }^{1}$, Rose Bechtel, and Jean-Xavier Guinard
}

\begin{abstract}
Additional Index words. consumer preferences, Citrus reticulata, Citrus sinensis, eating habits, fruit size, quality, seasonality

Summary. To identify factors that may reduce mandarin (Citrus reticulata) and orange (Citrus sinensis) consumer acceptance and to acquire information on current consumer thoughts and perceptions, a series of eight focus groups were held in a college town in northern California: four with children and four with adults. Adults mentioned cost proportionately more $(P \leq 0.05)$ often than children, as well as farm to fork, purchasing preferences, and seasonality. Children mentioned eating preferences, social use, and healthiness more often $(P \leq 0.05)$. Flavor and taste were important to both age groups, as well as ease of peeling. Both ages viewed oranges as slightly too large and messier than mandarins. Adults felt frustration that oranges and mandarins lack flavor and that quality is not consistent. Many indicated they would be willing to pay more for consistent quality. Children reported relying on availability, appearance, and the basic tastes to guide their choices and did not express a clear preference between mandarins and oranges. Development of a fruit intermediate in size between an orange and a mandarin, either a small orange or a large mandarin, would potentially satisfy an untapped area of the market. Other potential areas of consumer interest are in fruits with edible peels, like kumquats (Citrus japonica) and in more unique, identifiable varieties such as Cara Cara oranges.
\end{abstract}

I n 2017, California was the highest producer of fresh market citrus (Citrus sp.) in the United States, with more than 3 million tons (2.72 million megagrams) of fruit produced for fresh consumption [U.S. Department of Agriculture (USDA), 2018a]. Oranges were most of the fresh market citrus produced in California, followed in descending order by the categories of lemons (Citrus limon), tangerines (Citrus reticulata) and mandarins, and finally grapefruit (Citrus paradisi). Although lower than total production amounts of oranges, growers from California accounted for $\approx 96 \%$ of the fresh market category of tangerines and

Received for publication 19 Feb. 2019. Accepted for publication 22 Apr. 2019.

Published online 12 June 2019.

Department of Food Science and Technology, University of California, One Shields Avenue, Davis, CA 95616

This research was funded by a grant from the California Citrus Research Board to study consumer preferences for oranges and mandarins. We thank Kendon Kurzer for his assistance with qualitative methodology and coding.

${ }^{1}$ Corresponding author. E-mail: abkurzer@ucdavis. edu.

This is an open access article distributed under the CC BY-NC-ND license (https://creativecommons.org/ licenses/by-nc-nd/4.0/).

https://doi.org/10.21273/HORTTECH04320-19 mandarins produced in the United States in the 2017-18 season (USDA, $2018 \mathrm{~b}$ ). As citrus such as mandarins begin to decrease in acidity and acceptability starting only 3 weeks after harvest (Tietel, 2011), consumers of citrus closest to the harvest location likely are the most accustomed to higher-quality fruit. These consumers likely also have access to larger numbers of varieties and crosses, such as Meyer lemons (Citrus meyeri), which are less ideal for shipping and storage (Reuther and Webber, 1967). Because of their geographic proximity and high familiarity with numerous types and varieties of fresh citrus, consumers living in California may thus be considered to be lead-users of citrus, a term used to describe experienced consumers who are considered to be ahead of market trends (Schreier and Prügl, 2008). As a result, their habits and usage of oranges and mandarins can provide useful information for consumers in other parts of the country who buy and consume citrus.

One of the challenges with breeding and selecting varieties of citrus to grow for fresh consumption is that consumers themselves have difficulty identifying and selecting fruit that will meet their expectations, potentially making purchase choices based on appearance alone (Poole et al., 2007). Although data exist on the effect of analytical and sensory attributes on liking of mandarins and oranges (Campbell et al., 2004; Gao et al., 2011; Goldenberg et al., 2015; House et al., 2011; Ivans and Ferree, 1987; Obenland et al., 2009), as well as how consumers estimate valuation (Poole et al., 2007), many aspects of the consumer experience cannot be measured or described using quantitative research. Furthermore, many factors influence selection or consumption of fruits, and these factors are different for adults and children (Reinaerts et al., 2007).

In complement to existing quantitative research mapping sensory preferences for oranges and mandarins (Simons et al., 2018a, 2018b), we sought to better understand consumer preferences, usage, and needs for oranges and mandarins through a series of focus groups. Focus groups have been shown to be a useful tool in analyzing consumer behaviors and preferences with food, and have been used to analyze behaviors by age as well (Chambers et al., 2008; MacFie and Thomson, 1994). The objectives of this study were to identify factors that may adversely affect consumption of oranges and mandarins in both adults and children, as well as to identify the current and future needs of consumers regarding oranges and mandarins, of which there are few qualitative data. We hypothesized that peelability of the fruit, as well as presence of seeds, would be important factors, as well as freshness, in both adults and children, in agreement with existing data. We further hypothesized that the preferences for oranges vs. mandarins would be different in adults compared with children, and that children would express preferences for mandarins over oranges.

\section{Methods}

Eight focus groups were conducted with consumers from an educated, college town or surrounding area in northern California in the spring following the end of California's citrus season. Four focus groups were composed of four to six adults (18 participants total, 13 women and 5 men, ages 18-64 years) who 
purchased at least $50 \%$ of their household's groceries, and four focus groups were composed of three to nine children between the ages of 8 and 12 years old (23 participants total, 16 girls and 7 boys). For demographic information about the subjects, see Table 1.

Participants were recruited through flyers in public community areas, such as farmer's markets and community centers, social media, and through e-mail lists. Only children 8 to 12 years old were recruited to reduce developmental age differences between participants within a focus group. In addition to being the primary shopper (adults) or being in the correct age range (children), selection was determined by availability of the participants to attend one of the scheduled focus group times and by their liking and use of citrus. Although we attempted to balance gender, a higher proportion of respondents who identified as being the primary shopper were female. Most subjects were unrelated, although a few child participants were the children or siblings of other participants. Although the final number of participants was smaller than would have been preferred based on original recruitment, given the qualitative nature of the focus group interviews this number was sufficient to achieve redundancy, the typical sampling endpoint (Merriam, 2009). Furthermore, as small-scale interviewbased qualitative research is intended to be generative for concepts, the representativeness of the study sample is less crucial, as life experiences of individuals are not generalized to a larger group (Crouch and McKenzie, 2006). The aim of these focus groups was to identify factors that may reduce citrus consumption and to acquire information on current consumer thoughts and perceptions about oranges and mandarins.

Focus groups were conducted in a controlled environment with a twoway mirror led by a moderator and were recorded by video, audio, and transcribed. The first author served as the moderator for all focus groups. Sessions with adults lasted for $90 \mathrm{~min}$ and those with children lasted $60 \mathrm{~min}$. Participants responded to various questions about typical consumption habits, likes and dislikes, preferences, and overall opinions (Table 2).

Table 1. Demographic characteristics of adults and 8- to 12-year-old children participating in focus groups on oranges and mandarins.

\begin{tabular}{|c|c|c|c|c|c|}
\hline \multirow{2}{*}{ Characteristic } & & \multicolumn{2}{|c|}{ Children } & \multicolumn{2}{|c|}{ Adults } \\
\hline & & (no.) & $(\%)$ & (no.) & $(\%)$ \\
\hline \multirow[t]{5}{*}{ Age group (yr) } & $8-9$ & 8 & 35 & & \\
\hline & $10-12$ & 15 & 65 & & \\
\hline & $18-34$ & & & 8 & 44 \\
\hline & $35-54$ & & & 7 & 39 \\
\hline & $55+$ & & & 3 & 17 \\
\hline \multirow[t]{2}{*}{ Gender } & Female & 16 & 70 & 13 & 72 \\
\hline & Male & 7 & 30 & 5 & 28 \\
\hline \multirow[t]{6}{*}{ Ethnicity } & White/Caucasian & 14 & 61 & 9 & 50 \\
\hline & Asian & 2 & 9 & 5 & 28 \\
\hline & Hispanic/Latino(a) & 2 & 9 & 1 & 6 \\
\hline & Black/African American & 1 & 4 & 1 & 6 \\
\hline & Other & 2 & 9 & 0 & 0 \\
\hline & Prefer not to answer & 2 & 9 & 2 & 11 \\
\hline \multirow[t]{3}{*}{ Citrus-eating frequency } & Every day & 4 & 17 & 2 & 11 \\
\hline & 3-4 times per week & 4 & 17 & 7 & 39 \\
\hline & 1-2 times per week & 15 & 65 & 9 & 50 \\
\hline \multirow[t]{5}{*}{ Income } & Less than $\$ 10,000$ & & & 4 & 22 \\
\hline & $\$ 10,000-\$ 29,999$ & & & 5 & 28 \\
\hline & $\$ 30,000-\$ 79,999$ & & & 4 & 22 \\
\hline & $\$ 80,000+$ & & & 2 & 11 \\
\hline & Prefer not to answer & & & 3 & 17 \\
\hline \multirow[t]{5}{*}{ Education level } & Some college & & & 2 & 11 \\
\hline & 2-year degree & & & 2 & 11 \\
\hline & 4-year degree & & & 2 & 11 \\
\hline & Graduate degree & & & 9 & 50 \\
\hline & Professional degree & & & 3 & 17 \\
\hline
\end{tabular}

Table 2. General focus group script outline for adults and children regarding oranges and mandarins.
Greeting
Outline of study purpose
Instructions for participants
Explanation of research subject rights
Warm-up questions
Question set 1: Awareness and overall opinion of oranges
Question set 2: Where and when oranges eaten
Question set 3: Eating habits of oranges
Question set 4: Awareness and overall opinion of mandarins
Question set 5: When and where mandarins eaten
Question set 6: Eating habits of mandarins
Overall health benefits
Most desired change in citrus
Wrap-up questions
Dismissal

Adults as primary purchasers also were asked about affordability of citrus as well as purchase habits, whereas children were not. We developed the question sets using established principles for effective focus group questions (Merriam, 2009 ) to reveal the fruit characteristics that adults and children value. Questions sets also were pretested on small groups before use in the focus groups. Participants were compensated for their time with a gift card to an online retailer or to a local general merchandise store following the session, with sessions following institutional review board (IRB)-approved protocol (IRB no. 821014-1).

After transcription, we coded the scripts for parent- and childlevel themes that emerged using qualitative data analysis software 
that assists with coding (NVivo 12; QSR International, Melbourne, Australia), based on grounded theory (Strauss, 1987), and tabulated the results. We defined codable occurrences of the transcript as segments or whole sentences of a participant's dialogue focused on an individual concept. If a section of the dialogue contained more than one concept, it was coded for all relevant codes. In addition to general themes, we also coded attributes that were liked and disliked about the fruit and tabulated them. These coded occurrences for liked and disliked attributes were interpreted separately from the general themes. Reliability of the coding was evaluated by a second rater with experience coding in qualitative research double coding a subset of the focus group transcripts. The interrater agreement correlation (Pearson's $R$ ) for this subset was 0.86 .

To determine whether there were significant differences between tabulated codes for adults and children, counts for each thematic code were compared with the total number of all coded occurrences within that age group and converted to a proportion. This was done to account for the different number of total occurrences between adults and children due to the disparity in duration of the focus groups. We then compared the adult and child proportions for each thematic code using binomial tests with a Bonferroni correction adjusted for multiple comparisons with $\mathrm{R}$ statistical analysis software (R Core Team, Vienna, Austria).

In addition to coding, we summarized the general findings of the focus groups using multiple observations. An observer recorded the main findings during each session, and at the end of each session, the author acting as moderator wrote down key concepts observed as well. Two of the authors then independently summarized the key concepts after observing the focus groups and combined these results with the previously recorded findings. This information, along with the transcripts, was used to articulate the views of the participants.

\section{Results and discussion}

Thematic CODE FReQuency. Fifteen main coded themes emerged in the analysis (Table 3 ). In adults, the top three most frequently coded themes were quality and freshness of the fruit, followed by eating preferences and cost

(Fig. 1). In children, the most commonly coded concept was eating preferences, which included preferred preparation methods, habits,

Table 3. Definitions of main thematic codes from four adult $(n=18)$ and four child $(n=23)$ focus groups on oranges and mandarins.

\begin{tabular}{|c|c|}
\hline Thematic code & Meaning \\
\hline Quality and freshness & The perceived quality and freshness of the fruit. \\
\hline Eating preferences & $\begin{array}{l}\text { How the consumers prefer to eat the fruit including } \\
\text { typical eating habits. }\end{array}$ \\
\hline Cost & The tangible cost of buying the product. \\
\hline Social use & $\begin{array}{l}\text { Consumption and sharing of citrus in social } \\
\text { settings, including with family and friends. }\end{array}$ \\
\hline Varieties & Different varieties and types of citrus available. \\
\hline Versatility and utility & $\begin{array}{l}\text { Practical aspects of the fruit, such as portability and } \\
\text { cleanliness. }\end{array}$ \\
\hline Farm to fork & Local availability and sourcing of fruit. \\
\hline Healthiness & $\begin{array}{l}\text { The perceived health effects resulting from } \\
\text { consumption. }\end{array}$ \\
\hline Purchasing preferences & $\begin{array}{l}\text { The shopping habits of the consumers in buying } \\
\text { the fruit. }\end{array}$ \\
\hline Seasonality & How ripe and in season the fruit is. \\
\hline Peelability & $\begin{array}{l}\text { How easy the peel detaches from the fruit, as well as } \\
\text { the proportion of peel to fruit. }\end{array}$ \\
\hline Size of fruit & $\begin{array}{l}\text { References to the size of the fruit, whether big or } \\
\text { small. }\end{array}$ \\
\hline Consistency & $\begin{array}{l}\text { The degree to which the fruit varies from time to } \\
\text { time when purchasing. }\end{array}$ \\
\hline Availability & How accessible the fruit was to buy or eat. \\
\hline Novelty or fun & $\begin{array}{l}\text { The entertainment or fun factor that the fruit } \\
\text { provides while buying or eating. }\end{array}$ \\
\hline
\end{tabular}

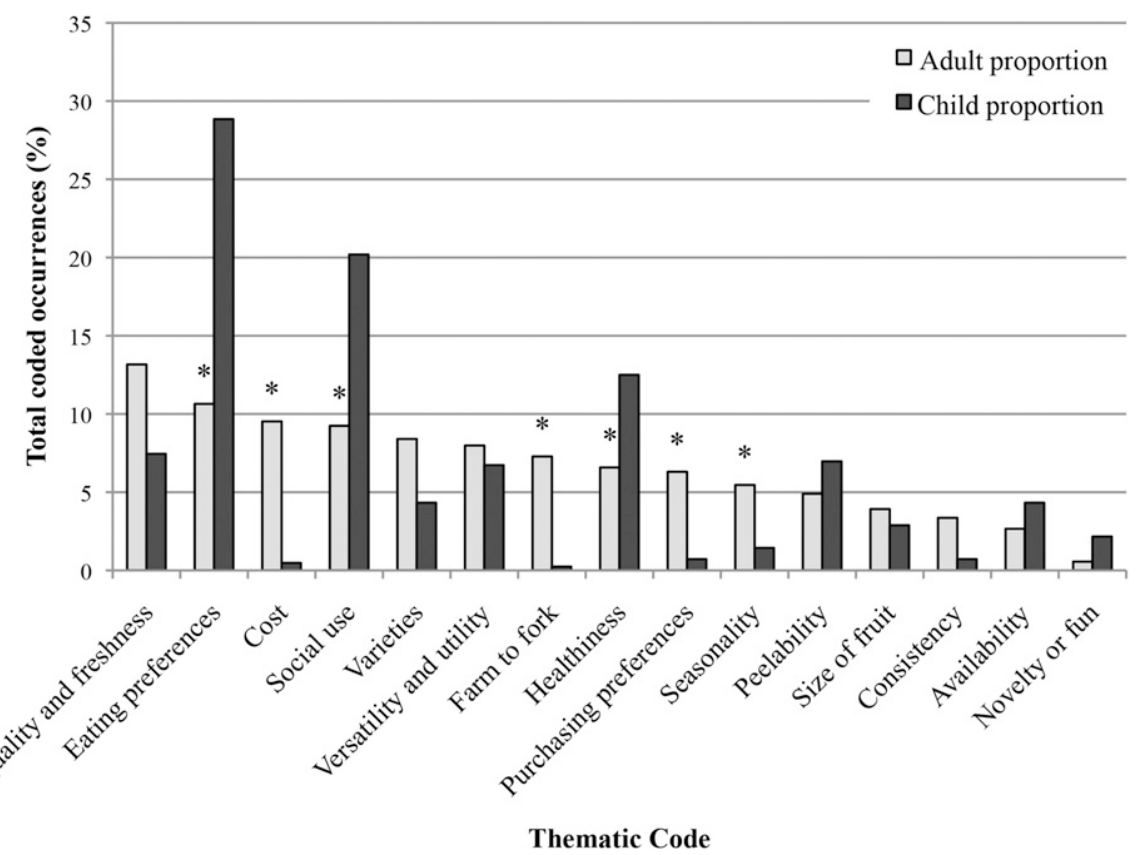

Fig. 1. Percentage of total coded occurrences by general thematic element from four adult $(n=18)$ and four child $(n=23)$ focus groups on oranges and mandarins. Asterisks indicate a significant difference between adults and children in the proportion of the coded utterances in that category by binomial test at $P \leq 0.05$ using a Bonferroni correction for family-wise error. 
and locations. The second most mentioned topic in children was social use of fruit, which was further clustered into the topics of sharing fruit, consumption with family, and friendship. The third highest frequency code in children was healthiness of the fruit. Figure 1 shows the differences in the frequency that the general thematic codes were assigned between adults and children, including significant differences in the percentages of total occurrences between the age groups.

Compared with the children, adults mentioned the cost proportionately more often $(P \leq 0.05)$, as well as farm to fork, purchasing preferences, and seasonality. This lower proportion of instances discussing these topics could be either there is less awareness of these topics in children or that they may be relatively less important to them. The children mentioned eating preferences, social use, and healthiness more often $(P \leq$ $0.05)$. Quality and freshness, varieties, versatility and utility, peelability, size of fruit, consistency, availability, and novelty and fun were mentioned equally frequently between the groups.

Table 4 shows the liked attributes that the consumers mentioned about the fruit for both the adults and children. In general, the flavor or taste of the fruit was the most mentioned attribute for both the children and the adults. After the flavor or taste, adults mentioned the appearance or color of the fruit second most, followed by the size of the fruit. For children, juiciness was rated second, followed by sweetness. In general, these liked attributes are largely in agreement with attributes deemed important by other studies of citrus (Baldwin et al., 2014; Gao et al., 2011).

In addition to the high number of occurrences of the concept of juiciness, the children also mentioned the concept of the fruit being refreshing, a concept that the adults never did, suggesting that the water content of the fruit may be a driving factor for liking in children more than for adults. In contrast, smell was mentioned more frequently by adults than by children as a positive attribute. This may be due to the effects of scent triggering more memories and nostalgia in adults than in children (Willander and Larsson, 2006).
Table 5 shows the disliked attributes coded for adults and children. The most frequently mentioned dislike by adults was the mess caused by eating oranges or mandarins. This was also the second most frequent coded dislike for children. Adults also made frequent mention of disliking dry texture. For children, the peel of the orange was one of the most frequently mentioned dislikes, as well as the mesocarp, or "white stuff." It is notable that seeds were not one of the highest mentioned dislikes in the focus groups. This may be a result of consumers typically consuming seedless fruit and not frequently encountering seeds, or in other words, it is not one of the problems they frequently encounter. We postulate that the frequency of mentioning disliking seeds may be higher in individuals typically eating fruit with more seeds.

QUAlity, FReShNeSS, AND VARIETIES. The most common complaint from adult consumers about the oranges was the lack of freshness and good quality. A variety of factors that are not consistent among all consumers are used to evaluate fruit freshness, including appearance of mold, juiciness of the fruit, and color. One of the key findings was that the adult consumers felt a strong disconnect between the appearance of the orange and the consistency of the fruit quality inside, citing small

Table 4. Thematic code occurrences for liked fruit properties from four adult $(\mathrm{n}=$ $18)$ and four child $(n=23)$ focus groups on oranges and mandarins.

\begin{tabular}{|c|c|c|c|}
\hline \multicolumn{2}{|c|}{ Adults } & \multicolumn{2}{|c|}{ Children } \\
\hline Thematic code & Occurrences (no.) $)^{\mathrm{z}}$ & Thematic code & Occurrences (no.) \\
\hline Flavor and taste & 19 & Flavor and taste & 30 \\
\hline Appearance and color & 15 & Juiciness & 15 \\
\hline Size & 13 & Sweetness & 11 \\
\hline Smell & 10 & Appearance and color & 10 \\
\hline Juiciness & 9 & Refreshing & 10 \\
\hline Sourness & 8 & Sourness & 8 \\
\hline Easy to peel & 7 & Size & 7 \\
\hline Sweetness & 7 & Firm texture & 6 \\
\hline Firm texture & 6 & Not messy & 6 \\
\hline Other & 6 & Easy to peel & 3 \\
\hline Not messy & 5 & Balanced flavor & 3 \\
\hline Balanced flavor & 3 & Other & 3 \\
\hline Entertainment & 3 & Smell & 2 \\
\hline Refreshing & 2 & Entertainment & 0 \\
\hline
\end{tabular}

${ }^{\mathrm{z}}$ Number of times a part or a whole sentence of the participant's dialogue focused on an individual concept.

Table 5. Thematic code occurrences for disliked fruit properties from four adult $(n=18)$ and four child $(n=23)$ focus groups on oranges and mandarins.

\begin{tabular}{lcllr}
\hline & Adults & & \multicolumn{2}{c}{ Children } \\
\cline { 5 - 5 } Thematic code & Occurrences (no.) & & Thematic code & Occurrences (no.) \\
\hline Messiness & 19 & Peel & 15 \\
Other & 15 & Messiness & 14 \\
Dry texture & 13 & Pith & 11 \\
Lacks flavor & 10 & Seeds & 9 \\
Old & 9 & Sourness & 7 \\
Pith & 8 & Effort & 6 \\
Peel & 7 & Bitterness & 5 \\
Seeds & 7 & Other & 5 \\
Effort & 6 & Dry texture & 3 \\
Too sweet & 6 & Lacks flavor & 3 \\
Waste & 5 & Too sweet & 3 \\
Boring & 3 & Waste & 3 \\
Bitterness & 3 & Old & 2 \\
Sourness & 0 & Boring & 0 \\
\hline
\end{tabular}

${ }^{\mathrm{z}}$ Number of times a part or a whole sentence of the participant's dialogue focused on an individual concept. 
proportions of fruit to mesocarp, desiccated flesh, and/or low flavor. One adult participant stated "It makes me angry when it's dry, fermented tasting, and not what I expected. It's like being poisoned." Some expressed frustration with the high proportion of peel present relative to the amount of fruit and the perceived waste of money and disappointment. Many indicated that to a point they would rather pay more for a higher quality, consistently flavorful product. Many indicated that purchase of poorquality oranges or mandarins makes them reluctant to purchase them in the future. Adults interviewed were familiar only with Navel-type oranges and 'Cara Cara' oranges, but expressed interest in newer varieties of oranges in part because they believed them to be of higher quality and consistency. For mandarins, Cuties (Sun Pacific, Pasadena, CA) and Halos (The Wonderful Co., Los Angeles, CA) were the only familiar brands, with no clear preference or brand loyalty.

Children were less able to describe distinguishing criteria for fresh vs. old fruit, and when asked to describe the difference, many did not remember ever having experienced citrus fruit that was not fresh. This could be either because parents do not give their children older, lower quality fruit, or because children are less sensitive to differences in freshness. For the children, it seemed that the quality of the fruit was more dependent on the amount of sweetness or sourness they perceived, or how well the citrus fit their ideal.

Poor quality of fruit has been cited as a potential reason for lower intake of fruits in some previous studies (Yeh et al., 2008). Average consumption of fruit in the United States has persisted at levels lower than recommendations given by the U.S. Dietary Guidelines (Guenther et al., 2006; U.S. Department of Health and Human Services and USDA, 2015). This is particularly worrisome, as fruit and vegetable consumption has been associated with a reduced risk of stroke, cardiovascular disease, and hypertension, among other diseases (Slavin and Lloyd, 2012). Citrus fruits are also good sources of compounds such as flavonoids, fiber, and vitamins that are typically lacking in the American diet (Turner and Burri, 2013). The feedback from these focus groups support the notion that quality and freshness of the fruit at the consumer level may be an important factor to consider in evaluating citrus consumption. Consequently, finding ways to increase the sensory appeal and perceived quality and freshness of oranges and mandarins at purchase and consumption may be important to increasing intake.

SEASONALITY AND FARM TO FORK. The adults interviewed expressed a strong preference for citrus that is in season, expressing uneasiness about the ripeness and quality of fruit available when it is not in season in California. Many participants also expressed that they wished that the season that fruit is sold would be shorter, with fruit sales discontinued when the fruit begins reaching the end of the season and begins to decline in quality. No participants mentioned differences in the seasonality of different varieties of citrus. The participants mostly agreed that the inseason citrus was superior in quality, taste, and cost compared with offseason. One participant stated, "in winter, when they're in season, they seem to be extra sweet." Despite this, one trend observed with seasonality was that even among these consumers who are fairly familiar with citrus being in season in the winter, there was a strong association of summer with citrus. This mismatch occurred despite many of those same participants stating that they preferred citrus that is locally in season.

Another trend that was observed was the frequent mention of locally sourced produce, coded under farm to fork. Adults in particular were very interested in oranges and mandarins from local sources, like local farms, farmer's markets, and neighborhood trees. This finding is consistent with past research showing a cluster of consumers who value sustainability and locally sourced produce (Yue and Tong, 2009; Yue et al., 2009, 2011). Generally, participants seemed to equate local sourcing with freshness, with the farther that the produce was shipped to their location, the less fresh the product. This may pose interesting challenges to fruit growers shipping long distances targeting consumers who value freshness.

Children associated citrus with being refreshing, and "sunshine." Similarly, one adult stated, "the smell, it's like summer." For the children, this is summed up well by one participant who said, "when I usually want them they're out of season, and not as good." If participants from an area such as this, likely familiar with the local winter citrus season, associate oranges and mandarins with summer, this association is likely to be even stronger among those users who are not as familiar. The low frequency with which seasonality was mentioned by the children suggests that children may be unaware of when citrus is in season. Similarly, the number of references to farm to fork also were low, indicating low awareness for where and when citrus is available locally.

Peelability. A child participant stated: "At school you can pick whatever you want. I don't eat oranges at school because I have a hard time peeling it. That it is why I prefer to eat mandarins at school." Children typically were interested in oranges that were easier to peel. They also expressed interest in edible peels, such as are found on kumquats, however. Similar to the children, the adults did not care for the citrus peels either, but were less receptive to novel ideas such as more edible peels. Many of the adults felt that the peel offered protection against pesticides and other contaminants, and although they liked the idea of reduced work peeling, were not willing to give up the protective qualities of the peel. A similar trend was seen by Campbell et al. (2006), who found a segment of the population they studied that generally disliked the concept of peeled and sectioned mandarins, possibly because of the idea of others touching their fruit. Many participants also expressed dislike of the thickness of the peel of the orange, citing the amount of food wasted considering the cost. Given that food trimmings are one of the larger sources of consumer waste (Scriven and Harrison, 1988), this may in part explain why consumers view fruit with large amounts of peel as wasteful.

Size OF FRUIT. Some participants expressed satisfaction about large fruit sizes, whereas others expressed preferences for smaller fruit. Preferences for larger fruit were mostly centered on the idea of it being juicy and visually appealing. Expressed preferences for smaller fruit were 
driven by multiple concepts, such as quantity of food, waste, and nostalgia. Children indicated they are unable to finish large oranges and adults said that they both feel unwilling to commit to a large orange and have memories of smaller fruit. An adult participant stated: "I think growing up oranges were smaller and more manageable to put in a lunch. It was the size of an apple. It's more like a grapefruit now." Another stated "The size. I won't buy a big orange because they're messy and not as juicy as you think. It's mostly pith and skin." For participants who expressed these opinions, oranges were considered generally to be too large.

Most adults felt that mandarins are too small to share, although some children said that they share mandarins. Some felt that the ideal size for fruit would be somewhere in the middle of the size of a mandarin and the size of an orange. An adult participant stated, "I would wish that they were bigger, because they don't fill me up." There was a perception that the size of a mandarin was closer to the ideal amount of fruit for a child: "My kids don't want a whole large orange in their lunches."

Future development of citrus fruit that is intermediate in size between mandarins and oranges, either small oranges or large mandarins, seems to be a place in the market that is not being satisfied by either oranges or mandarins. Additional named varieties, such as Cara Cara oranges, also may be a source of future growth and consumer interest, as well as for citrus with less bitter and more edible peels to appeal to both adults and children who feel the peel is being wasted. Widespread awareness of brands, such as Cuties and Halos, indicates that this is an effective marketing strategy for mandarins and could be successful with oranges as well if a variety was to be branded and marketed that way.

Social use. Children viewed citrus consumption as a social activity, possibly in part because of their lack of ability to prepare the fruit themselves. A child participant said, "I eat with my mom because I see her eating one and want one." Adults, in contrast, viewed oranges as more socially disruptive, and as something that is more difficult to eat in a social setting because of its strong smell during peeling. Adults felt that the smell may either disturb others or unintentionally invite them to share, some even peeling their oranges at home to reduce the smell later. For sharing fruit, most adults felt mandarins were too small to share, whereas oranges were viewed as a generally more shareable fruit than mandarins because of their larger size. However, some children felt that mandarins were a good size to share despite their size, and many reported sharing these with parents or siblings.

EAting PREFerences. Portability and convenience were some of the main appealing characteristics of citrus cited by adults. Some noted that oranges can be more difficult to transport than mandarins in purses or bags because of the large size, making mandarins a more appealing choice to pack. Oranges are usually eaten in a place where the mess can be disposed of and hands can be cleaned: near a sink, outside, or at home.

Children indicated that they do not want to spend much time peeling or preparing fruit and frequently eat or share citrus prepared by parents. Some children do not perceive messiness to be a deterring factor for oranges, but others strongly object to the cleanup required. Although some children peel an orange and eat it themselves, others rely solely on caregivers to peel or cut oranges for them. Children see whole and half circle slices as being more fun, whereas adults viewed the slices as being more effort and mess. All age groups expressed liking for the peeled segments due to familiarity, even though they considered them to be less attractive in presentation.

Adult participants who were parents also perceived mandarins as less messy and more child friendly, whereas children did not necessarily see mandarins as being better. In children, consumption seems to be largely driven by the availability of fruit or juice. It was reported that some parents and schools do not buy oranges and some do not buy mandarins, limiting which fruits the children are able to eat. Child perceptions of which fruits are best may be affected by which fruits they see going uneaten. One child told a story about numerous uneaten mandarins in the "free" box at school. Based on their observation, they assumed that no one liked mandarins at their school.
For time of consumption, oranges and mandarins were considered to be most appropriately eaten around breakfast, lunch-time, or as a snack, although oranges as orange juice were frequently reported for breakfast and oranges were mentioned as something eaten with or after dinner. Mandarins were more often described as a snack than oranges. However, little mention was made of consumption of oranges as a dessert, so they seem to be mostly categorized as a snack-type food, particularly among adults.

Although some participants made their own orange juice using oranges purchased at the store, most purchased orange juice presqueezed or did not drink orange juice. Orange juice was thought to be lacking a fresh-squeezed flavor by most adults and many expressed that they would be more willing to buy and drink orange juice if it had more or better flavor. There was also a prevalent perception that orange juice contains added non-natural flavors, is overly processed, and "fake." Adults also perceived that orange juice was lacking in value, as it was missing other healthy components of the fruit. Children generally perceived that orange juice is not purchased because of the high sugar content, but would drink it if it were available. The concern about too much sugar was even mentioned a few times regarding the fruit itself. However, adult reasoning appears to be more complex, as they perceive orange juice as being expensive, low in fresh juice aroma, and high in sugar, and would not necessarily drink it given the option, unlike almost all of the children who would. This finding that orange juice is viewed as somewhat unhealthy was interesting. However, it is possible that if orange juice had been discussed concurrently with less nutrient-dense sweetened beverages like soft drinks, it would have been described as healthier.

Healthiness. When asked about the health benefits of citrus, some adults were aware of some benefits, such as vitamin $\mathrm{C}$, phytochemicals, and fiber content, but did not consider those benefits to be as high of a priority: "I assume it has vitamin $\mathrm{C}$ and it tastes great and makes me feel good. I don't worry too much about the nutrition." In comparison with 
the adults, the children had a significantly higher proportion of coded occurrences regarding health benefits. When asked the same questions, some children knew vitamin $\mathrm{C}$ is in citrus but many could not identify why its presence would be beneficial to their health or why they needed it. Some children also reported that orange juice is less healthy than orange fruit, because of its higher sugar content. Children appeared to be still developing an understanding of the health effects of citrus and may be relying strongly on their parents' or teachers' knowledge.

Purchase preferences. When in season, most adults found the quality of oranges to be acceptable, and the prices to be affordable, although some still indicated that they would like to see a lower price. Threeand 5-pound bags of mandarins sold in stores were reported as being too large for single adults to finish before they become old and unappealing, which sours the impulse to buy another bag. It was suggested that smaller bags or bulk purchase, while potentially less cost-effective, would allow for purchase of more manageable amounts of fruit. As citrus is typically one of the least expensive types of fruit, it is logical that consumers purchasing citrus based on the cost would be interested in reducing food that wastes money due to spoilage. Existing literature supports this idea as well, showing that different segments of the population prefer different packaging methods in the grocery store (Campbell et al., 2006). Mandarins were seen as less variable in quality when in season and more variable in quality when out of season, less available out of season, and sold in less manageable quantities. When out of season, participants expressed that they felt the citrus available that had been shipped from other countries was of lower quality than inseason locally grown citrus.

Some adults perceived mandarins as a children's snack, because of the size. There is also a perception that mandarins go bad or mold more quickly. As one adult participant stated, "Why get a mandarin when you can just get an orange?" Others expressed a wish to have more variety available to buy, such as more new varieties like Cara Cara and greater availability of less common fruits like pomelos (Citrus grandis). A small subset of the group also vocalized that they preferred more acidic and astringent fruit, which finding would be in line with the findings of Simons et al. (2018a), who identified a cluster of consumers who like sour fruit.

Before the focus groups, we hypothesized that adults and children would differ in their preferences for mandarins as compared with oranges, with adults preferring oranges and children preferring mandarins. However, based on the discussion in the focus groups, it would seem that the preferences for oranges or mandarins are not as simply defined. There were some children who were sure that they preferred oranges to mandarins based on flavor. The idea that children prefer mandarins may stem from the idea that oranges are considered too big for children, both by some children and by some parents. This is an interesting dilemma: although some aspects of a fruit, such as size, may not be as significant as flavor for liking (House et al., 2011), they may still play a role in use of the fruit in context. Although they may view two differently sized oranges equally when evaluated for taste, a parent may be less likely to place a large fruit into their child's lunchbox. The adult participants repeatedly commented on the size of the fruit being too large when thinking about a fruit to eat; it is likely they would feel the same if they were giving it to a child.

Parents also seem to have a large role in cultivating which fruits their children are accustomed to. As a result, parental opinions on the suitability of fruits for their children may be as or more important than sensory attributes for children. This is particularly notable given that some children reported preferring a type of citrus, either oranges or mandarins, not currently purchased in their household. As children ages 2 through 11 years eat $\approx 15 \%$ of the total fresh oranges consumed in the United States, these are viewpoints that have great value (Pollack et al., 2003).

Messiness. Although participants in general consistently mentioned messiness as a dislike, dislike of mess came up more frequently in reference to oranges than mandarins. One adult participant stated, "I could eat a mandarin anywhere, not so with oranges." Another stated, "When I'm home, I have time and I can wash my hands after, so that's when I eat oranges." Yet another participant stated, "I wouldn't eat an orange, it's too messy." Many mentioned that they preferred to eat oranges and mandarins near a sink or outside to minimize the mess created. Notably, when asked about where they preferred to eat oranges, one child stated, "Outdoors because it's juicy and messy, and if you're outside it's ok." Similarly, many commented that oranges should be juicy but not too juicy to prevent making a mess. This finding is in agreement with other research that shows messiness has a deleterious effect on liking of a food (Zellner et al., 2011). We might hypothesize that mess that involves direct contact and requires cleaning up would have an even greater negative effect.

The "PERFECT" ORANGE. Adults preferred oranges to be juicy, but not to the point of messiness. They also expressed strong preference for consistency and quality of flavor in oranges. Many indicated a preference for local fruit, especially from local neighborhood trees, or delivered organic produce because of the higher freshness, quality, and knowledge of location. One suggestion was for a fruit that is larger than a mandarin, which is perceived to be child snacksize, and smaller than an orange, which is too intimidating and large.

Children reported that they generally like citrus because it is considered sweet, sour, juicy, and refreshing. When asked to describe their ideal orange or mandarin, children described it as being sweet with perfect round shape, and juicy; it would also be easy to peel and seedless. These findings are similar to other published data in which these attributes were important for mandarins (Bi et al., 2012; House et al., 2011). Oranges with balanced sourness and sweetness that are not too sour or bitter were described as being ideal. There was a general dislike of the white mesocarp, segment fibers, and peeling the fruit in general. Although children are frequently assumed to like mandarins more, many expressed a preference for oranges given the choice, but eat oranges and mandarins based on availability at home or school. Some 
suggestions that children had for improvements in citrus would be to create a smaller size orange as well as to create a variety in which you can eat the peel.

KEY DIFFERENCES BETWEEN ADULTS AND CHILDREN. In general, adults were more concerned with the flavor, quality, and price of oranges or mandarins. In tastes, the children were more concerned about the basic flavors and the presence of deterring visual factors such as the albedo or "white part" and seeds. Adults indicated more selectivity when it comes to oranges, eating based on intensity and quality of flavor as well as price, whereas children were more concerned with the basic tastes of sourness and bitterness, as well as presence of mesocarp and pulp, seeds, and other visual cues. Children also were more focused on who would eat and prepare oranges, mandarins, and juice with them, as well as by competition from other foods. Children also were more concerned with effort of preparation of the oranges for consumption, possibly because of less experience than adults in peeling and cutting.

Children were generally less inhibited in eating oranges placed in front of them, viewing it as a social activity, and are more willing to eat fruit they deem less than ideal. Many children liked the idea of a fun, edible, less bitter peel, similar to a kumquat, that eliminates the need for peeling, but adults preferred a more practical peel that can be discarded to protect the fruit from pesticides and outside contamination. In general, and expectedly, adult reasoning appeared to be generally more complex and multifaceted and children's perception was based on what required the least amount of effort, was sweetest, and most fun.

\section{Conclusions}

Adults felt that orange and mandarin quality is not consistent and would be willing to pay more for consistent quality and flavor. Both adults and children had a strong dislike of messiness in their fruit. Adults and children both also felt that oranges are currently slightly too large. Children may rely on fruit supplied by family or school, as well as appearance and the basic tastes to guide their choices. In this study, they did not seem to have a clear general preference between mandarins and oranges, contrary to our previous hypothesis that children would express preference for mandarins. Development of a fruit intermediate in size between an orange and mandarin, either a small orange or a large mandarin, would potentially fulfill an untapped area of the market. Other potential areas of consumer interest are in fruits with edible peels and in more new identifiable varieties, such as Cara Cara.

\section{Literature cited}

Baldwin, E.A., J. Bai, and A. Plotto. 2014. Citrus fruit quality assessment: Producer and consumer perspectives. Stewart Postharvest Rev. 10(2):1-7.

Bi, X., L. House, Z. Gao, and F. Gmitter. 2012. Sensory evaluation and experimental auctions: Measuring willingness to pay for specific sensory attributes. Amer. J. Agr. Econ. 94:562-568.

Campbell, B.L., R.G. Nelson, R.C. Ebel, and W.A. Dozier. 2006. Mandarin attributes preferred by consumers in grocery stores. HortScience 41:664-670.

Campbell, B.L., R.G. Nelson, R.C. Ebel, W.A. Dozier, J.L. Adrian, and B.R. Hockema. 2004. Fruit quality characteristics that affect consumer preferences for satsuma mandarins. HortScience 39: 1664-1669.

Chambers, S., A. Lobb, L.T. Butler, and W.B. Traill. 2008. The influence of age and gender on food choice: A focus group exploration. Intl. J. Consum. Stud. 32:356-365.

Crouch, M. and H. McKenzie. 2006. The logic of small samples in interview-based qualitative research. Soc. Sci. Info. 45:483-499.

Gao, Z., L.O. House, F.G. Gmitter, Jr., M.F. Valim, A. Plotto, and E.A. Baldwin. 2011. Consumer preferences for fresh citrus: Impacts of demographic and behavioral characteristics. Intl. Food Agribus. Mgt. Rev. 14:23-40.

Goldenberg, L., Y. Yaniv, T. Kaplunov, A. Doron-Faigenboim, N. Carmi, and R. Porat. 2015. Diversity in sensory quality and determining factors influencing mandarin flavor liking. J. Food Sci. 80:S418-S425.

Guenther, P.M., K.W. Dodd, J. Reedy, and S.M. Krebs-Smith. 2006. Most Americans eat much less than recommended amounts of fruits and vegetables. J. Amer. Dietetic Assn. 106:1371-1379.
House, L.A., Z. Gao, T.H. Spreen, F.G. Gmitter, M.F. Valim, A. Plotto, and E.A. Baldwin. 2011. Consumer preference for mandarins: Implications of a sensory analysis. Agribusiness 27:450-464.

Ivans, E. and M. Ferree. 1987. Earlyseason navel oranges may be too sour for consumers. Calif. Agr. 41(1):20-21.

MacFie, H.J. and D.M. Thomson. 1994. Measurement of food preferences. Springer-Verlag, Berlin, Germany.

Merriam, S.B. 2009. Qualitative research: A guide to design and implementation. 3rd ed. Wiley, San Francisco, CA.

Obenland, D., S. Collin, B. Mackey, J. Sievert, K. Fjeld, and M.L. Arpaia. 2009. Determinants of flavor acceptability during the maturation of navel oranges. Postharvest Biol. Technol. 52:156-163.

Pollack, S., B.-H. Lin, and J.E. Allshouse. 2003. Characteristics of U.S. orange consumption. U.S. Dept. Agr. FTS 305-01.

Poole, N.D., L.M.-C. Martínez, and F.V. Giménez. 2007. Quality perceptions under evolving information conditions: Implications for diet, health and consumer satisfaction. Food Policy 32:175-188.

Reinaerts, E., J. de Nooijer, M. Candel, and N. de Vries. 2007. Explaining school children's fruit and vegetable consumption: The contributions of availability, accessibility, exposure, parental consumption and habit in addition to psychosocial factors. Appetite 48:248-258.

Reuther, W. and H.J. Webber. 1967. The citrus industry. Vol. 1. Univ. California, Div. Agr. Sci., Berkeley.

Schreier, M. and R. Prügl. 2008. Extending lead-user theory: Antecedents and consequences of consumers' lead userness. J. Prod. Innov. Mgt. 25:331-346.

Scriven, F.M. and R. Harrison. 1988. Pilot study of consumer wastage of horticultural produce. Food Qual. Prefer. 1: 43-46.

Simons, T., H. Sivertsen, and J.-X. Guinard. 2018a. Mapping the preferences of adult and child consumers for California-grown mandarins. HortScience 53:1029-1037.

Simons, T., H. Sivertsen, and J.-X. Guinard. 2018b. Mapping the preferences of adult and child consumers for Californiagrown navel oranges. HortScience 53: 661-668.

Slavin, J.L. and B. Lloyd. 2012. Health benefits of fruits and vegetables. Adv. Nutr. Intl. Rev. J. 3:506-516.

Strauss, A.L. 1987. Qualitative analysis for social scientists. Cambridge Univ. Press, New York, NY. 


\section{Research Reports}

Tietel, Z., A. Plotto, E. Fallik, E. Lewinsohn, and R. Porat. 2011. Taste and aroma of fresh and stored mandarins. J Sci. Food Agr 91:14-23.

Turner, T. and B.J. Burri. 2013. Potential nutritional benefits of current citrus consumption. Agriculture 3:170-187.

U.S. Department of Agriculture. 2018a. QuickStats: Summary of 2017 citrus totals, fresh market production, measured in tons. 22 Oct. 2018. <https://quickstats. nass.usda.gov/results /460FCF67A4AC-3EAl-B5E9-E73939B23BB6>

U.S. Department of Agriculture. 2018b. Citrus fruits 2018 summary: August 2018. 29 Oct. 2018. <https://www.nass. usda.gov/Publications /Todays_ Reports/reports/cfrt0818.pdf>.
U.S. Department of Health and Human Services and U.S. Department of Agriculture. 2015. 2015-2020 Dietary guidelines for Americans. 8th ed. 29 Oct. 2018 <https://health.gov/dietaryguidelines/ 2015/resources/2015-2020_Dietary_ Guidelines.pdf>.

Willander, J. and M. Larsson. 2006. Smell your way back to childhood: Autobiographical odor memory. Psychon. Bull. Rev. 13:240-244.

Yeh, M.-C., S.B. Ickes, L.M. Lowenstein, K. Shuval, A.S. Ammerman, R. Farris, and D.L. Katz. 2008. Understanding barriers and facilitators of fruit and vegetable consumption among a diverse multiethnic population in the USA. Health Promot. Intl. 23:42-51.
Yue, C., F. Alfnes, and H.H. Jensen. 2009. Discounting spotted apples: Investigating consumers' willingness to accept cosmetic damage in an organic product. J. Agr. Appl. Econ. 41:29-46.

Yue, C., J.H. Dennis, B.K. Behe, C.R. Hall, B.L. Campbell, and R.G. Lopez. 2011. Investigating consumer preference for organic, local, or sustainable plants. HortScience 46:610-615.

Yue, C. and C. Tong. 2009. Organic or local? Investigating consumer preference for fresh produce using a choice experiment with real economic incentives. HortScience 44:366-371

Zellner, D.A., E. Siemers, V. Teran, R. Conroy, M. Lankford, A. Agrafiotis, L. Ambrose, and P. Locher. 2011. Neatness counts. How plating affects liking for the taste of food. Appetite 57:642-648. 